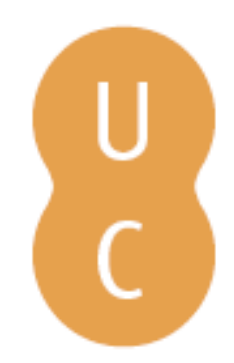

\title{
nombalina
}

\section{Encuentros Ibéricos de EDIBCIC, una corta historia para una interesante idea}

Autor(es): $\quad$ Borges, Maria Manuel; Sanz-Casado, Elias

Publicado por: Imprensa da Universidade de Coimbra

URL

persistente: URI:http://hdl.handle.net/10316.2/31848

DOI: $\quad$ DOI:http://dx.doi.org/10.14195/978-989-26-0319-3_2

Accessed : $\quad$ 26-Apr-2023 08:27:50

A navegação consulta e descarregamento dos títulos inseridos nas Bibliotecas Digitais UC Digitalis, UC Pombalina e UC Impactum, pressupõem a aceitação plena e sem reservas dos Termos e Condições de Uso destas Bibliotecas Digitais, disponíveis em https://digitalis.uc.pt/pt-pt/termos.

Conforme exposto nos referidos Termos e Condições de Uso, o descarregamento de títulos de acesso restrito requer uma licença válida de autorização devendo o utilizador aceder ao(s) documento(s) a partir de um endereço de IP da instituição detentora da supramencionada licença.

Ao utilizador é apenas permitido o descarregamento para uso pessoal, pelo que o emprego do(s) título(s) descarregado(s) para outro fim, designadamente comercial, carece de autorização do respetivo autor ou editor da obra.

Na medida em que todas as obras da UC Digitalis se encontram protegidas pelo Código do Direito de Autor e Direitos Conexos e demais legislação aplicável, toda a cópia, parcial ou total, deste documento, nos casos em que é legalmente admitida, deverá conter ou fazer-se acompanhar por este aviso. 
Maria Manuel Borges

Elias Sanz Casado

Coordenação

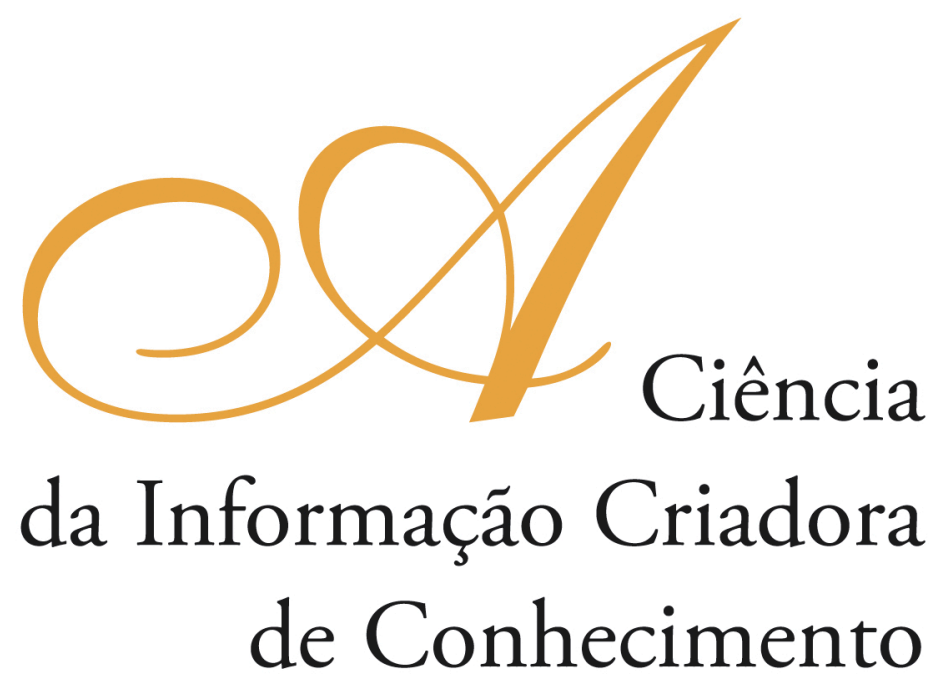

Vol. I

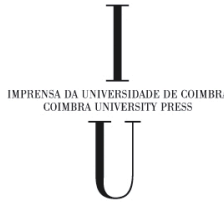

- COIMBRA 2009 


\section{ENCUENTROS IBÉRICOS DE EDIBCIC, UNA CORTA HISTORIA PARA UNA INTERESANTE IDEA}

Este próximo Encuentro de EDIBCIC Ibérico que se celebra en la Universidad de Coimbra constituye el IV congreso regional de la asociación que tiene lugar en la península Ibérica. Hasta ahora dos de ellos han tenido su sede en España y otros dos (con este último) en Portugal. La iniciativa para la realización de estos eventos partió de la Asociación de Educación e Investigación en Ciencia de la Información de Iberoamérica y el Caribe (EDIBCIC), cuyos coordinadores regionales quisieron dinamizar la actividad científica española y portuguesa así como fomentar la colaboración en las áreas implicadas en la Ciencia de la Información. Otro de los objetivos implícitos en la celebración de estas jornadas era el de potenciar la presencia de los investigadores y docentes de estos dos países en todas las actividades de la asociación iberoamericana.

La forma más eficiente de mejorar el mundo, es mejorar el entorno que nos rodea. Formamos parte de un sistema complejo e invisible de vasos comunicantes que nos aproxima a los otros a través de objetivos comunes que nos obligan a buscar las soluciones necesarias. En este sentido, creemos que si somos capaces de hacer propuestas atractivas de investigación y docencia sobre los temas en los que estamos trabajando en la región, seremos capaces de aportar ese conocimiento al resto de países iberoamericanos que participan en la asociación, con el fin de enriquecer y facilitar a todos ese acervo común.

La región Iberoamericana constituye un espacio amplio y diverso, en el que compartimos cultura, tradiciones e intereses comunes en muchos temas de investigación. Todo ello nos permite explorar nuevas iniciativas y colaborar para aportar soluciones que amplíen nuestro conocimiento. Con esta finalidad, decidimos crear un espacio de comunicación científica que nos permitiera intercambiar las experiencias investigadoras y docentes que íbamos realizando en las universidades y centros de investigación portugueses y españoles. Decidimos que cada dos años, en una ciudad de cada uno de los dos países, se canalizara parte de la actividad científica desarrollada en nuestro quehacer diario.

El primer encuentro regional se celebró el año 2003 en la Facultad de Biblioteconomía y Documentación de la Universidad de Salamanca. La celebración de este encuentro inició el proceso de colaboración y se propuso mantener en el tiempo la posibilidad de comunicación entre los docentes e investigadores de universidades y centros de información de los dos países. En este esfuerzo queremos reconocer en el profesor José 
Antonio Frías, su excelente voluntad pionera para abrir y mantener esta nueva vía de comunicación. Sin duda ha sido uno de los protagonistas que ha trabajado con mayor ahínco por consolidar este encuentro bianual dentro del panorama de la Ciencia de la Información de la región Ibérica.

A este encuentro asistimos un puñado de colegas portugueses y espańoles que, durante un día, buscamos y discutimos temas de interés coincidente con los distintos objetivos de la investigación y la docencia de ambos países. El compromiso firme y decido de continuar con la idea de mantener estos encuentros, permitió albergar el compromiso de reunirse dos años después en la ciudad portuguesa de Oporto.

La profesora Fernanda Ribeiro, tomó el reto de organizar en 2005 el II Encuentro de la sección Ibérica de EDIBCIC, en la Facultad de Letras de la Universidad de Oporto. Este encuentro contó con la participación de un grupo más nutrido de profesores e investigadores de ambos países que trabajaban en el área de Ciencia de la Información, y que expusieron durante un día sus trabajos de investigación. Este segundo encuentro nos permitió constatar que la idea estaba cuajando, y que no sólo era posible mantener este tipo de reuniones en el tiempo, sino que se estaba despertando el interés de otros profesionales e investigadores que se estaban sumando a la iniciativa.

Esta realidad se constató en el III Encuentro en la ciudad española de Salamanca, en la que esta vez, y a "Ao volante do Chevrolet pela estrada de Salamanca", título de estas jornadas que se celebraron durante 3 días, participó un gran número de profesionales e investigadores, que ya no se limitaron al entorno español o portugués, sino que, desde distintos países latinoamericanos, vinieron a compartir con nosotros sus trabajos de investigación. Se puede decir que este fue el punto de encuentro donde se vislumbró de manera real que esta iniciativa había empezado a tomar vida dentro del panorama iberoamericano de la Ciencia de la Información. De algún modo, es un evento que ya se esperaba y que estaba empezando a ocupar parte del calendario de actividades de los investigadores en este campo de conocimiento. Otro hecho significativo que, de manera silenciosa se iba constatando, y que constituía uno de los objetivos originales de estas celebraciones, era la colaboración entre los investigadores de los dos países ibéricos. En este sentido, que este tercer encuentro estuviera dirigido por los profesores José Antonio Frías y Fernanda Ribeiro constataba que se estaba consiguiendo este objetivo.

Ahora y dos años después de aquel evento, nos proponemos con vosotros celebrar el IV Encuentro. En este caso en la Facultad de Letras de la Universidad de Coimbra. Para ello, hemos elegido como tema del encuentro "Las relaciones entre la Ciencia de la Información y otras áreas de conocimiento: el papel de la Ciencia de la Información a nivel universitario". El motivo de elegir como temas tanto la transversalidad como el papel de la Ciencia de la Información en el ámbito universitario, ha sido por un lado, el de reconocer la importancia que ha tenido y tiene en su desarrollo los conocimientos provenientes de otras disciplinas, que han estado presentes desde sus orígenes, y que aún continúan nutriendo los conocimientos que se generan en la Ciencia de la Información. El otro aspecto que queremos resaltar es el del papel que juega esta disciplina en el ámbito universitario. En este sentido, creemos que es cada vez mayor su relevancia y que merece la pena analizarlo. Es importante constatar cómo se está produciendo un viaje de ida y vuelta, de tal manera que los conocimientos generados en la Ciencia de 
la Información empiezan a introducirse y calar, mediante un proceso de capilaridad en otras disciplinas, formando parte del entramado universitario.

Este cuarto encuentro regional de EDIBCIC ha continuado con la tradición del anterior y ha saltado también las fronteras de la península Ibérica, recibiendo propuestas de participación de investigadores y profesionales del ámbito de la Ciencia de la Información de un gran número de países iberoamericanos. En total, el número de propuestas que hemos recibido ha sido casi de 200. Por tanto, podemos decir que la idea primitiva del encuentro se ha consolidado, que hemos conseguido entre todos participar en los objetivos de un colectivo, que como comentábamos al principio, constituimos un espacio amplio y diverso, pero en el que compartimos cultura, tradiciones e intereses comunes en muchos temas, entre ellos los de investigación y docencia.

No tenemos ninguna duda de que las aportaciones que se hagan en este encuentro y que estarán configuradas en distintos apartados, como son: el estatuto epistemológico de la Ciencia de la Información, la Ciencia de la Información y la formación en el contexto Ibérico bajo la influencia de Bolonia, la perspectivas de investigación, y, finalmente, el diálogo entre la formación y la sociedad, pasarán a engrosar ese conocimiento común que ya compartimos en EDIBCIC.

Finalmente, sólo nos queda agradecer a todos los que han participado en la organización de Encuentro su generoso esfuerzo, que esperamos se vea recompensado por los resultados científicos y profesionales que, sin duda, se conseguirán.

\section{Maria Manuel Borges (Universidad de Coimbra) Elias Sanz-Casado (Universidad Carlos III de Madrid) Directores do IV Encuentro Coimbra, Noviembre de 2009}

